\title{
A influência de diferentes contextos de intervenção na escrita de histórias por crianças ${ }^{1}$
}

\author{
The influence of different instructional contexts \\ on children's story writing
}

\author{
Sulamita Pires FERREIRA² \\ Jane CORREA ${ }^{2}$
}

\section{Resumo}

Investigou-se a influência de contextos de intervenção envolvendo atividades de natureza metatextual na escrita de histórias por crianças. No primeiro contexto de intervenção foram realizadas atividades que destacavam a estrutura narrativa das histórias, além de incentivar as crianças a refletirem sobre as características próprias deste gênero textual a partir de duas histórias-exemplo. No segundo contexto, além da atividade de reflexão acerca da organização hierárquica da narrativa de história realizada a partir de uma única história-exemplo, foi também realizado um levantamento de temas para a escrita de novas histórias. Os resultados mostraram um desenvolvimento significativo na qualidade da escrita de histórias das crianças que participaram dos contextos de intervenção, em comparação àquelas que não participaram das atividades.

Uniterms: Desenvolvimento da linguagem. Histórias. Psicolingüística.

\begin{abstract}
The study investigates the influence of instructional contexts involving metatextual activities in the writing of stories by children. In the first instructional context, activities were conducted which highlighted the narrative structure of the stories and which encouraged the children to discuss critically the characteristics of a story by taking two stories as examples. In the second context, besides the activity of reflecting on the hierarchical organization of the story's narrative conducted using just one sample story, the children were also asked to brainstorm ideas for a new story. The results showed a significant improvement in the quality of story writing with the children who participated in the instructional contexts compared to those who participated in a control group.
\end{abstract}

Uniterms: Language Development. Story. Psycholinguistics.

1 Artigo elaborado a partir da dissertação de S.P. FERREIRA, intitulada "A Influência de diferentes contextos de intervenção sobre a escrita de histórias por crianças". Programa de Pós-Graduação em Psicologia, Universidade Federal do Rio de Janeiro; 2006. Bolsista: Coordenação de Aperfeiçoamento de Pessoal de Nível Superior.

2 Universidade Federal do Rio de Janeiro, Instituto de Psicologia, Programa de Pós-Graduação em Psicologia. Av. Pasteur, 250, Urca, 22290-240, Rio de Janeiro, RJ, Brasil. Correspondência para/Correspondence to: S.P. FERREIRA.E-mails: <sulapires@gmail.com>; <correa@psicologia.ufrj.br>.

Agradecimentos aos apoios da Fundação de Amparo à Pesquisa do Estado do Rio de Janeiro e do Conselho Nacional de Desenvolvimento Científico e Tecnológico. À Secretaria Municipal de Educação do Rio de Janeiro, à escola e a seus professores, pela acolhida, e em especial às crianças, por sua valiosa participação.
} 
A habilidade de escrita está relacionada não só à freqüência com que as pessoas escrevem, mas à valorização da escrita no contexto social, à importância atribuída ao texto escrito e à familiaridade com diferentes gêneros de texto (Garcez, 2002). Gêneros de texto são produções sócio-comunicativas e funcionais relativamente estáveis, caracterizadas por estilo, conteúdo e composição que Ihes são próprias (Marcushi, 2002). 0 emprego dos gêneros textuais contribui para a estruturação das interações estabelecidas no cotidiano (Bazerman, 2006). São inúmeros os gêneros textuais, por exemplo: o bilhete, a lista de compras, o e-mail, o blog, a notícia, entre outros. Neste trabalho, o interesse está voltado para um gênero textual em particular: a história. Apesar das diferenças teóricas quanto às características da história como um gênero textual, a estrutura de uma história prototípica inclui basicamente três elementos principais: início, desenvolvimento e desfecho (Spinillo, 2001; Stein, 1982). De uma maneira geral, acredita-se que uma história deva ter um início, no qual ocorre a introdução da cena e dos personagens; um desenvolvimento, em que se desenrola uma situação-problema, isto é, um conflito ou um acontecimento que mobilize os personagens; e um fim, que traz o desfecho da situação-problema ou a solução do conflito.

A habilidade de elaborar histórias é influenciada pela idade e escolaridade da criança (Albuquerque \& Spinillo, 1997; Spinillo \& Pinto, 1994). Ao longo de sua escolaridade, as crianças tendem a escrever histórias mais elaboradas, ou seja, histórias em que haja a introdução da cena e dos personagens, a inclusão de uma situação-problema à narrativa e um desfecho razoavelmente articulado ao restante da história (Spinillo, 2001). Apesar de importantes, a idade e a escolaridade não são os únicos fatores a serem considerados no desenvolvimento de histórias por crianças. Outro fator que se revela de fundamental importância quando se trata da habilidade de produzir histórias pelas crianças é o que se denomina de contexto ou situação de produção, isto é, as condições em que a criança é solicitada a elaborar a sua história. De forma geral, contextos de produção que oferecem alguma forma de apoio à criança, seja este apoio visual, por uma seqüência de gravuras (Shapiro \& Hudson, 1991; Spinillo, 2001) ou lingüístico (Lins e Silva \& Spinillo, 2000), para a reprodu-

548 ção escrita de uma história anteriormente lida, tendem a propiciar a escrita de textos de estrutura narrativa mais elaborada.

O fato de existirem crianças de mesma série escolar produzindo histórias com diferentes níveis de complexidade narrativa, enquanto outras têm desempenho semelhante em diferentes contextos de produção, sugere o exame de outros fatores que possam, juntamente com a idade, escolaridade e contexto de produção influenciar a escrita de histórias pelas crianças. Lins e Silva e Spinillo (2000) agruparam crianças com idades entre sete e dezanos, alunos da primeira à quarta série do Ensino Fundamental, em função de seu desempenho na escrita de histórias, em quatro contextos: a) produção livre: a criança era solicitada a escrever uma história original; b) oral/escrita: a criança elaborava oralmente uma história original e depois escrevia esta mesma história; c) seqüência de gravuras: a criança produzia uma história a partir de uma seqüência de gravuras que sugeria uma situação-problema; e d) reprodução: a criança escrevia seu texto a partir de uma história lida pelo examinador.

No primeiro nível foram reunidas as crianças que produziam histórias elementares e incompletas em todos os contextos. No segundo nível estavam as crianças que produziam histórias mais elementares diante das condições de produção livre e oral/escrita, mas que diante das situações de seqüência de gravuras e reprodução apresentavam histórias com estrutura narrativa elaborada. As crianças alocadas no terceiro nível produziam histórias elaboradas diante das diferentes situações de produção.

O nível 1 reuniu exclusivamente crianças da primeira e da segunda séries. No segundo nível, uma fase intermediária, havia crianças de todas as séries, embora com predomínio das mais novas (45\% das crianças da $1^{\text {a }}$ série, $60 \%$ das crianças da 2a série, 15\% das crianças da 3a série e $25 \%$ das crianças da 4a série). No nível 3 a situação se inverteu, em função da presença da maioria das crianças da $3^{a}$ e $4^{a}$ séries. Lins e Silva e Spinillo (2000) tomaram estes três níveis como a expressão do domínio do esquema narrativo pelas crianças. Em um nível mais elementar de domínio do esquema narrativo, a criança não é capaz de produzir histórias completas diante dos vários contextos; no intermediário, a qualidade de suas histórias depende da situação de produção e, no mais avançado, as crianças fazem 
histórias completas diante de todas as situações de produção. A influência que o contexto de produção exerce sobre a escrita da criança depende, então, do quão desenvolvido é o domínio do esquema narrativo pelas crianças.

Uma forma eficaz de promover o desenvolvimento do esquema narrativo em crianças, segundo Ferreira e Spinillo (2003), seria pela realização de atividades relacionadas à consciência da organização hierárquica da narrativa de histórias. Se isto for possível significa, de acordo com Ferreira e Spinillo (2003), estabelecer uma conexão entre o desenvolvimento da consciência metatextual e a produção de texto, de forma que quanto maior o nível de consciência da criança sobre a estrutura e organização da narrativa de histórias, mais coerente e coeso é o texto por ela elaborado. 0 desenvolvimento da consciência metatextual, definida como a capacidade de reflexão sobre a estrutura do texto (Gombert,1992), permitiria ao sujeito tratar o texto como objeto de análise, desviando sua atenção da mensagem e seus significados para focalizá-la predominantemente em sua estrutura e organização.

Fayol (1985) argumenta, por outro lado, que a capacidade de refletir sobre a estrutura e organização do texto, por se tratar de um processo mais complexo, é em si posterior à habilidade de produção do texto, uma vez que implica em um processo de tomada de consciência. Como decorrência, é possível a produção de histórias coerentes por crianças que tenham conhecimento apenas intuitivo do esquema narrativo, o que seria conseguido a partir da experiência da criança com a leitura e produção de histórias.

Ferreira e Spinillo (2003) testaram então a hipótese de que a habilidade de produzir histórias seria passível de ser desenvolvida por meio de atividades de natureza metatextual, ou seja, de atividades que conduzissem as crianças à reflexão acerca das características estruturais de um determinado gênero textual, neste caso, as histórias. Foram propostas a crianças de sete e oito anos atividades que, realizadas individualmente, incluíam a instrução e identificação das partes de histórias, a complementação de histórias incompletas e a montagem de histórias. Foram procedimentos empregados nas sessões de intervenção: a) leitura em voz alta do texto pelo examinador com a criança, a fim de minimizar possíveis dificuldades de decodificação; b) possibilidade de repetição das tarefas, conforme a necessidade; c) solicitação de justificativas para as respostas dadas pelas crianças; e d) feedback imediato às respostas das crianças, com explicações acerca de seu desempenho nas tarefas, tanto no caso de erro quanto no caso de acerto. Contrastando com o grupo controle, as crianças que participaram das sessões de intervenção passaram a contar, quando não histórias completas, histórias que, apesar de seu desfecho abrupto, incluíam o delineamento de uma situação-problema. Assim, a partir dos resultados obtidos pela intervenção realizada por Ferreira e Spinillo (2003), é possível concluir que a habilidade de produzir histórias, pelo menos para textos elaborados de forma oral, possa ser desenvolvida a partir do emprego de atividades de natureza metatextual.

Expandindo a temática abordada por Ferreira e Spinillo (2003) pretendeu-se, neste trabalho, analisar a influência de contextos de intervenção que envolvam atividades de natureza metatextual sobre a produção escrita de histórias por crianças. Em particular, objetivouse examinar a eficácia de situações de intervenção que levassem a criança a identificar, analisar e refletir sobre os componentes estruturais prototípicos de histórias, quando realizadas em grupo, no desenvolvimento da escrita de histórias por crianças nas primeiras séries do Ensino Fundamental. A escolha por atividades em grupo justifica-se por estas constituírem contextos de aprendizado passíveis de serem aplicados posteriormente ao aprendizado das crianças em sala de aula.

Com base na literatura descrita anteriormente (Ferreira \& Spinillo, 2003; Spinillo \& Simões, 2003), um contexto de intervenção produtivo que possa auxiliar a criança na escrita de histórias mais elaboradas deveria: a) informar explicitamente às crianças sobre a estrutura própria de uma história e mostrar que esta estrutura é comum a todas as histórias prototípicas; e b) dar às crianças a oportunidade de refletir, participando de maneira ativa e reflexiva das atividades desenvolvidas.

Nesse sentido, foram analisados neste estudo dois contextos de intervenção, visando ao desenvolvimento da escrita de histórias por crianças. No primeiro contexto foram realizadas atividades que buscaram destacar a estrutura narrativa das histórias, além de incentivar as crianças a refletirem sobre as características próprias deste gênero textual. No segundo contexto, 
além da atividade de reflexão acerca da organização hierárquica da narrativa de histórias, foi também realizado um levantamento de temas para as mesmas. 0 levantamento de temas para a escrita de histórias é uma prática pedagógica amplamente realizada nas salas de aula. Neste segundo contexto, porém, buscouse, a partir dos diferentes temas, refletir sobre a estrutura e organização hierárquica das histórias, começando com a discussão das possíveis formas de introdução dos personagens e da cena, de situações-problema e de desfechos diversos. Este segundo contexto de intervenção poderia se apresentar como o mais adequado, com melhores resultados, uma vez que além da reflexão acerca da estrutura narrativa em história-exemplo estariam disponíveis para as crianças diferentes possibilidades geradas pela transposição da organização hierárquica das histórias em temas para novas narrativas.

\section{Método}

\section{Participantes}

Tomaram parte do estudo 73 crianças de uma escola da cidade do Rio de Janeiro que atende a comunidades de status socioeconômico médio-baixo (amostragem por conveniência): 39 crianças cursavam a primeira série do Ensino Fundamental (média - $M=7,8$ anos; desvio-padrão - DP=3 meses) e 34 crianças cursavam a segunda série ( $M=8,6$ anos; $D P=4$ meses). $A$ participação das crianças foi autorizada por seus responsáveis, professores e demais profissionais da equipe pedagógica da escola. A participação foi voluntária, podendo a criança desistir de participar em qualquer etapa da pesquisa.

\section{Procedimentos}

Como pré-teste, foi pedido inicialmente às crianças que escrevessem uma história inventada por elas, em suas respectivas salas de aula. O tempo para a escrita da história foi livre, mas, de maneira geral, as crianças levaram cerca de quarenta minutos para escrever suas histórias. As histórias foram classificadas em cinco categorias: uma referente à produção de textos que não fossem histórias, e outras quatro categorias relacionadas a níveis crescentes de complexidade no domínio pela criança das convenções de escrita de

550 história. Foram tomadas como referência as categorias de análise presentes na literatura, especificamente aquelas descritas por Rego (1986) e Lins e Silva e Spinillo (2000), detalhadas na seção Resultados.

Os textos foram distribuídos em categorias por dois juízes independentes, sendo 86\% o coeficiente de concordância entre eles. As discordâncias foram apresentadas a um terceiro juiz, cuja decisão foi tomada como definitiva. As crianças, em cada um dos níveis em que sua produção foi classificada, foram distribuídas aleatoriamente em três grupos: dois experimentais (GE1 e GE2), correspondendo a cada um dos dois contextos de intervenção planejados, e um grupo de controle (GC).

As intervenções foram realizadas na própria escola. A título de pós-teste, cerca de vinte dias após a série de quatro intervenções para os grupos experimentais foi pedido a todas as crianças, em sala de aula, que escrevessem uma história inventada por elas mesmas. As histórias elaboradas pelas crianças na ocasião do pós-teste foram classificadas segundo a mesma categorização empregada para a classificação das histórias no momento do pré-teste. Os textos foram distribuídos em categorias por dois juízes independentes, sendo 84\% o coeficiente de concordância entre eles. Novamente, as discordâncias foram apresentadas a um terceiro juiz, cuja decisão foi tomada como definitiva.

\section{Contextos de intervenção}

Foram planejados dois contextos de intervenção. Cada grupo experimental participou das atividades de um único contexto de intervenção. Desta forma, o grupo experimental 1 (GE1) realizou as tarefas do contexto de intervenção 1, e o grupo experimental 2 (GE2) realizou as tarefas do contexto de intervenção 2. A distribuição das tarefas pelos contextos foi idealizada de modo que as crianças de ambos os grupos realizassem a mesma quantidade de atividades, possibilitando desta forma a comparação da eficácia dos dois contextos de produção de histórias.

Em ambos os contextos de intervenção, inicialmente arrolou-se o conhecimento que as crianças tinham sobre histórias. A primeira história foi lida junto a elas, e um pequeno resumo oral do texto lido foi feito para facilitar a sua compreensão. Logo após, iniciou-se a reflexão sobre o esquema prototípico de história, informando e discutindo com as crianças sobre as partes 
constitutivas da história e sua organização hierárquica: a introdução dos personagens e a descrição do lugar; descrição e desenvolvimento da situação-problema e desfecho da história. A atividade seguinte foi a releitura da primeira história por três vezes, para que as crianças pudessem identificar qual parte da história estaria faltando em cada um das releituras: uma vez faltando o início da história, outra, o desenvolvimento, e outra, o desfecho da trama. Foi pedido às crianças que justificassem suas respostas. As respostas das crianças foram seguidas de feedback do pesquisador sobre seus erros e acertos.

Após tais atividades, para as crianças que participaram do contexto de intervenção 1 (GE1) foi lida uma segunda história e pedido que identificassem o início, o desenvolvimento e o final da narrativa, justificando suas respostas. Foi dado feedback às crianças em relação a seus acertos e erros. Para finalizar, comparou-se a primeira e a segunda histórias, mostrando às crianças que ambas possuíam estrutura e organização hierárquica semelhantes.

Para o contexto de intervenção 2 (GE2), o passo seguinte após a realização das atividades iniciais foi construir com as crianças um roteiro de história. Assim, a partir de temas sugeridos pelas crianças foram elaboradas junto a elas duas alternativas de introdução, formas como cada uma das histórias poderia ser desenvolvida e possibilidades de desfecho para cada um dos temas apresentados, pela transposição dos conhecimentos anteriormente discutidos acerca da estrutura e organização da narrativa de histórias.

\section{Resultados}

Os textos produzidos pelas crianças nos pré e pós-testes foram classificados em cinco categorias derivadas das categorizações apresentadas por Rego (1986) e Lins e Silva e Spinillo (2000), conforme descritas a seguir. Na apresentação dos exemplos em cada uma das categorias foram inseridos alguns sinais de pontuação ou a grafia convencional de algumas palavras entre colchetes, visando facilitar a leitura das histórias produzidas pelas crianças.

Categoria Não-histórias: os textos aqui categorizados correspondiam a outros gêneros de texto que não a história. Foram incluídos relatos, descrições, transcrições de versos e letras de música ou produções este- reotipadas nas quais a criança escreveu algumas sentenças justapostas.

Categoria história l: foram incluídas nesta categoria aquelas histórias que se limitavam a fazer uma introdução do cenário e dos personagens. Em muitas histórias desta categoria encontravam-se expressões típicas de começo de histórias infantis, como "Era uma vez": "Era uma vez um macaco muito levado ele so [só] pensava em banana se pendurava no galho de árvore e brincava sem para [parar] com o elefante, tamandoa [tamanduá], onça, tigre, eleão. Fim".

Categoria história Il: nas histórias incluídas nesta categoria, já era possível identificar o início de uma ação ou um acontecimento que sugeria o esboço de uma situação-problema.

"O sapo encantado

Era uma vez um sapo, ele era muito bonzinho um dia ele tinha visto uma princesa chorando bua [buá], bua, bua. O sapo que falava disse: porque choraste [?] a princesa falou [:] um sapo falante. - Sim [,] eu falo [!] porque [?] te encomoda [?] [-] não, não é porque nunca vi um sapo falante".

Categoria história III: nesta categoria encontramse os textos que apresentaram um desfecho para a história, sem ser possível ainda identificar com clareza no texto a seqüência de eventos que levaram ao término da história, a partir da relação meios-fins sugerida. Muitas histórias terminavam ainda de forma abrupta, incluindo os marcadores lingüísticos típicos de um final de história como "e viveram felizes para sempre" e "fim" para assim dar por terminada a narrativa.

"Era uma vez uma flor que queria muito se casar com um rapaz. Mas tem um detalhe que ela era muito feia que [a] bruxa transformo [transformou] enenhum [rapaz] queria se casar com ela. Mais, ai [ai] ela teve uma idéia [:] ela voi [foi] no salão e vez [fez] uma maquiagem e ficou muito linda e se casou com lindo rapaz".

Categoria história IV: o diferencial desta categoria em relação à anterior é que aqui foram incluídas as histórias que apresentaram uma estrutura narrativa mais elaborada, tornando facilmente identificáveis as partes constituintes da história. Há, nos textos, a presença de uma situação-problema bem definida e um desfecho interligado ao restante da história.

"O jardim mágico e a flor triste

Era uma vez um jardim que moravam duas crianças o nome delas eram: Julha e João [.] aí uma vez uma flor 
sentiu-se triste [.] aí Julha foi molhar as flores eviu ela triste alieela perguntrou [perguntou]:

- Por que você está triste?

Aflorrespondeu:

- Á [Ah], é porque á [há] dias que faz muito sol e assim minhas flores vão queimar.

EJulhafalou:

- Ora! não fica triste não[.] vou pegar você [e] botar em um jaro [jarro] e vou botarvocêlá dentro de casa aívocê vai ficar ali até chover [.] quando chover você vai voutar [voltar] para ficar com suas amigas.

Duas semanas depois...

Choveu e ela voutou para o jardim.

Eassim eles viveram felizes párea cempre [para sempre]

Fim".

As 73 crianças que tomaram parte do estudo foram aquelas cujas histórias foram classificadas no préteste até a categoria III, uma vez que a classificação das histórias na categoria IV, classificação máxima, já seria indicativa da produção escrita de uma história mais elaborada. ATabela 1 apresenta a classificação dos textos produzidos pelas crianças no pré-teste.

Para efeito da análise estatística, foram atribuídos pontos de 0 a 4 às histórias produzidas pelas crianças, de acordo com sua classificação nas categorias anteriormente mencionadas. Desta forma, por exemplo, foram atribuídos 0 pontos, pontuação mínima, para os textos classificados como não-histórias, e a pontuação máxima (4 pontos) para os textos classificados na categoria história IV. A pontuação obtida para os textos produzidos pelas crianças no pré-teste foi submetida à Análise de Variância Não-Paramétrica (Kruskal-Wallis). Testes não-paramétricos foram empregados nesta análise, como nas subseqüentes, em função do número de textos produzidos (corpus de análise) e de sua classificação não se conformar à distribuição normal.
O emprego desta análise não indicou diferença significativa no desempenho escrito no pré-teste entre os grupos de controle $(M=1,58 ; D P=1,16)$, experimental $1(M=1,5 ; D P=1,00)$ e experimental $2(M=1,6 ; D P=0,99)$ no que se refere à produção de histórias na primeira série $(H(2)=0,81 ; p=96)$. Tal análise também não revelou diferença significativa no pré-teste no nível de elaboração das histórias escritas pelos grupos de controle $(M=1,73 ; D P=0,79)$, experimental $1(M=1,67 ; D P=0,78)$ e experimental $2(M=1,55 ; D P=0,82)$ na segunda série $(\mathrm{H}(2)=0,46 ; p=.79)$.

O resultado da categorização realizada para os textos produzidos pelas crianças no pós-teste pode ser examinado naTabela 2. Observa-se que, diferentemente dos grupos experimentais (GE1 e GE2), nenhuma criança do grupo controle produziu uma história classificada na categoria IV.

A exemplo da análise do desempenho escrito das crianças no pré-teste, foram atribuídos pontos às histórias no pós-teste de acordo com sua classificação nas categorias anteriormente descritas (Tabela 3). Foram, então, realizadas duas análises: a primeira estabelecendo a comparação entre o desempenho das produções escritas das crianças pré e pós-intervenção; a segunda, comparando o desempenho entre os grupos experimentais e de controle no pós-teste.

\section{Diferenças no desempenho das crianças nas produções escritas pré e pós-intervenção}

Foram comparadas as produções escritas pré e pós-intervenção com o objetivo de avaliar a eficácia da intervenção realizada, tomando como referência o desempenho das crianças consigo próprias. A comparação entre os desempenhos dos grupos experimentais e de controle nas produções livres pré e pós-intervenção para cada série foi realizada aplicando-se o teste de

Tabela 1. Distribuição das histórias por categoria no pré-teste. Rio de Janeiro (RJ), 2005.

\begin{tabular}{|c|c|c|c|c|c|c|c|c|c|c|c|c|}
\hline \multirow{4}{*}{ Categorias } & \multicolumn{12}{|c|}{ Pré-teste } \\
\hline & \multicolumn{6}{|c|}{ 1a série } & \multicolumn{6}{|c|}{ 2a série } \\
\hline & \multicolumn{2}{|c|}{$G C(n=12)$} & \multicolumn{2}{|c|}{ GE1 $(n=12)$} & \multicolumn{2}{|c|}{ GE2 $(n=15)$} & \multicolumn{2}{|c|}{$\mathrm{GC}(\mathrm{n}=11)$} & \multicolumn{2}{|c|}{ GE1 $(n=12)$} & \multicolumn{2}{|c|}{ GE1 $(n=11)$} \\
\hline & $n$ & $\%$ & $n$ & $\%$ & $n$ & $\%$ & $n$ & $\%$ & $n$ & $\%$ & $n$ & $\%$ \\
\hline Não-história & 3 & 25 & 2 & 17 & 2 & 13 & 1 & 9 & 1 & 8 & 1 & 9 \\
\hline História I & 2 & 17 & 4 & 33 & 4 & 33 & 2 & 18 & 3 & 25 & 4 & 36 \\
\hline História II & 4 & 33 & 4 & 33 & 5 & 33 & 7 & 64 & 7 & 58 & 5 & 45 \\
\hline História III & 3 & 25 & 2 & 17 & 3 & 20 & 1 & 9 & 1 & 8 & 1 & 9 \\
\hline
\end{tabular}

552

GC: Grupo controle; GE1: Grupo experimental 1; GE2: Grupo experimental 2. 
Tabela 2. Distribuição das histórias por categoria no pós-teste. Rio de Janeiro (RJ), 2005.

\begin{tabular}{|c|c|c|c|c|c|c|c|c|c|c|c|c|}
\hline \multirow{4}{*}{ Categorias } & \multicolumn{12}{|c|}{ Pós-teste } \\
\hline & \multicolumn{6}{|c|}{ 1a série } & \multicolumn{6}{|c|}{ 2a série } \\
\hline & \multicolumn{2}{|c|}{$G C(n=12)$} & \multicolumn{2}{|c|}{ GE1 $(n=12)$} & \multicolumn{2}{|c|}{ GE2 $(n=15)$} & \multicolumn{2}{|c|}{$G C(n=11)$} & \multicolumn{2}{|c|}{ GE1 $(n=12)$} & \multicolumn{2}{|c|}{ GE2 $(n=11)$} \\
\hline & $n$ & $\%$ & $\mathrm{n}$ & $\%$ & $\mathrm{n}$ & $\%$ & $\mathrm{n}$ & $\%$ & $\mathrm{n}$ & $\%$ & $\mathrm{n}$ & $\%$ \\
\hline Não-história & 1 & 8 & & & 1 & 7 & 1 & 9 & & & & \\
\hline História I & 4 & 33 & & & & & 1 & 9 & & & & \\
\hline História II & 4 & 33 & 3 & 25 & 2 & 13 & 7 & 64 & 5 & 42 & 4 & 36 \\
\hline História III & 3 & 25 & 7 & 58 & 11 & 73 & 2 & 18 & 6 & 50 & 6 & 55 \\
\hline História IV & & & 2 & 17 & 1 & 7 & & & 1 & 8 & 1 & 9 \\
\hline
\end{tabular}

GC: Grupo controle; GE1: Grupo experimental 1; GE2: Grupo experimental 2.

Tabela 3. Média de pontos obtida pelas crianças nas histórias escritas no pós-teste. Rio de Janeiro (RJ), 2005.

\begin{tabular}{|c|c|c|c|c|}
\hline \multirow{3}{*}{ Grupos } & \multicolumn{4}{|c|}{ Pós-teste } \\
\hline & \multicolumn{2}{|c|}{ 1a série } & \multicolumn{2}{|c|}{ 2a série } \\
\hline & $M$ & $\mathrm{DP}$ & $M$ & DP \\
\hline Controle & 1,75 & 0,97 & 1,91 & 0,83 \\
\hline Experimental & 2,92 & 0,67 & 2,67 & 0,65 \\
\hline Experimental 2 & 2,73 & 0,88 & 2,73 & 0,65 \\
\hline
\end{tabular}

M: média; DP: desvio-padrão.

Wilcoxon Signed Ranks, prova estatística não-paramétrica para comparação de dois grupos relacionados. Os resultados da análise não revelaram diferença significativa no desempenho do grupo controle (GC) nos dois momentos em que as produções escritas das crianças foram tomadas, tanto para a primeira série $(z=-0,37$, $p=0,70)$, como para a segunda série $(z=-0,55, p=0,58)$. Por outro lado, houve diferença nos textos escritos pelas crianças nas condições pré e pós-intervenção para os grupos experimentais. Para a primeira série, observouse diferença significativa para o grupo experimental 1 $(z=-2,58 ; p=0,01)$ e para o grupo experimental $2(z=-2,85$, $p=0,004)$. Na segunda série, tanto o contexto de produção 1 (GE1) $(z=-2,40 p=0,02)$ quanto o contexto de produção 2 (GE2) $(z=2,40 p=0,02)$ provocaram mudanças significativas na produção escrita das crianças. Em ambos os contextos de intervenção, a maioria das crianças passou a escrever histórias que incluíam o desenvolvimento de uma situação-problema e um desfecho, mesmo que ainda não explicitando os meios para a solução da situação-problema.

\section{Comparação das produções escritas no pós-teste entre os grupos experimentais e de controle}

A última etapa da análise contemplou a comparação das produções escritas no pós-teste entre os grupos experimentais e de controle, visando avaliar a eficácia das intervenções realizadas quando comparadas entre si e com a experiência escolar cotidiana das crianças representada pelo grupo de controle. Os resultados obtidos nas situações pós-intervenção foram submetidos à Análise de Variância Não-Paramétrica (Kruskal-Wallis). A análise revelou que as diferenças encontradas entre os grupos experimentais e de controle na produção escrita das crianças foram estatisticamente significativas tanto para a primeira série $(H$ $(2)=10,89, p=0,004)$ como para a segunda série $(H(2)=6,97$, $p=0,03$ ). As médias apresentadas na Tabela 3 não sugerem a existência de diferença apreciável no desempenho das crianças nos contextos de intervenção 1 e 2 em ambas as séries. Uma vez que os resultados da Análise de Kruskal-Wallis foram significativos, isto indica que a diferença entre os valores-médios extremos são significativos, sem necessidade de aplicação de novo teste visando à comparação deste par de médias (Tabela 3). Desta forma, na primeira série, o grupo experimental 1 (GE1) difere significativamente do grupo controle (GC) e, na segunda série, o grupo experimental 2 (GE2) difere significativamente do grupo controle (GC). O teste MannWhitney U foi usado para as comparações restan-tes. Na primeira série, a produção escrita do grupo experimental 2 (GE2) difere significativamente da do grupo controle (GC) ( $\left.U=38,000, N_{1}=12, N_{2}=15, p=0,01\right)$ no pósteste. Na segunda série, o grupo experimental 1 (GE1) difere significativamente do grupo controle (GC) $\left(U=33,500, N_{1}=11, N_{2}=12, p=0,04\right)$ no pós-teste. Desta forma, em ambas as séries encontraram-se diferenças significativas entre os grupos experimentais e de controle no pós-teste, embora os grupos experimentais entre si não guardassem diferença expressiva.

\section{Discussão}

Foi examinada a influência de contextos de intervenção que envolviam a realização de atividades 
de natureza metatextual sobre a escrita livre de histórias por crianças nas duas primeiras séries do Ensino Fundamental. No primeiro contexto, as crianças receberam instruções explícitas e discutiram sobre a estrutura narrativa em duas histórias-exemplo, realizando ainda atividades de identificação das partes constituintes de ambas as histórias. No segundo contexto, as crianças receberam instruções explícitas e discutiram sobre a estrutura narrativa em uma história-exemplo, realizaram atividade de identificação das partes constituintes da história-exemplo e discutiram sobre a organização hierárquica de histórias a partir de novos temas, sugeridos pelas próprias crianças, para a escrita de novas histórias.

O desempenho das crianças foi comparado em dois momentos da escrita livre de histórias: antes e depois de uma série de quatro sessões em cada contexto de intervenção. As produções escritas das crianças dos grupos experimentais foram também comparadas às produzidas pelas crianças do grupo de controle. Quando comparado o desempenho das crianças antes da série de intervenções e vinte dias após o término da última intervenção, constatou-se que houve uma mudança significativa na escrita de histórias pelas crianças que participaram dos grupos experimentais. No início do estudo, as crianças que participaram da pesquisa tiveram a maior parte das suas produções escritas classificadas nas categorias I (início de história) ou II (histórias que incluíam esboço de situação-problema), tanto para a primeira quanto para a segunda série. Em média, 59\% das histórias escritas no pós-teste pelas crianças que participaram dos contextos de intervenção concentraram-se nas categorias III (histórias com início, desenvolvimento e desfecho abrupto). Dez por cento, em média, das crianças de ambas as séries que participaram das atividades de intervenção produziram histórias classificadas na categoria IV (histórias completas).

Tais resultados mostram que os contextos de intervenção foram capazes de ajudar a maioria das crianças a escrever histórias completas por meio da promoção de um maior domínio do esquema narrativo. Outro indicativo de que as crianças tornaram-se mais atentas à estrutura narrativa das histórias que estavam produzindo veio do depoimento espontâneo das próprias professoras, que informaram que as crianças que fizeram parte do grupo experimental passaram a fazer uso dos conhecimentos desenvolvidos durante as

554 sessões de intervenção nas atividades de sala de aula.
As professoras observaram também que as crianças que participaram do estudo, muitas vezes, quando solicitadas a escrever histórias, comentavam que estas precisavam ter início, meio e fim. Ao produzirem seus textos em sala de aula, algumas crianças pulavam linhas entre as partes das histórias para marcar cada uma das etapas, ou escreviam as palavras começo, meio e fim, distribuindo-as às margens do caderno ou folha de redação antes de começarem a escrever, como forma de auxiliálas no desenvolvimento da narrativa. A partir do que observaram em suas turmas, as professoras passaram a realizar regularmente as atividades metatextuais planejadas para a presente intervenção como instrumento para o desenvolvimento da escrita de história por suas crianças.

Em média, 69\% das histórias das crianças que participaram das intervenções apresentaram um final relacionado à situação problema, enquanto a porcentagem média de tais histórias para o grupo controle foi de $21 \%$. A presença de um desfecho nas histórias das crianças tem sido apontada como um diferenciador de histórias bem elaboradas (Spinillo \& Martins, 1997). Os marcadores lingüísticos típicos de contos infantis, como "Foram felizes para sempre" e "Fim", são geralmente usados pelas crianças como forma de criar um desfecho para suas histórias, solução esta que, na maioria das vezes, resulta na finalização abrupta da narrativa. Estes marcadores lingüísticos são, muitas vezes, os elementos aos quais as crianças se referem na identificação e entendimento da estrutura hierárquica da história. Evidências empíricas sobre as idéias que as crianças entre cinco e nove anos têm sobre o que seria uma história e quais seriam os critérios por elas utilizados para enquadrar textos nesta categoria, indicam que as crianças tendem a aceitar como histórias textos incompletos ou sem nexo que incluem a presença de marcadores lingüísticos típicos dos contos infantis (Rego, 1996; Albuquerque \& Spinillo, 1997).

Ao serem informadas sobre a estrutura narrativa de histórias e levadas a refletir sobre a estrutura e organização do texto, as crianças foram expostas a um contexto de aprendizado propício ao domínio do esquema narrativo de forma intencional. Contrastando com o grupo controle, um número expressivo de crianças que participou das sessões de intervenção passou a produzir histórias mais bem elaboradas, com a presença de um desfecho integrado à narrativa. Os contextos de intervenção apresentados neste estudo levaram as crianças a revisarem as suas crenças sobre quais seriam as características de uma história, bem 
como a elaborarem seus conhecimentos sobre este gênero textual.

Os bons resultados encontrados por Ferreira e Spinillo (2003) para a produção oral de histórias em crianças de primeira e segunda séries podem também se estender à produção escrita de histórias. As atividades de natureza metatextual seriam uma boa alternativa pedagógica ao desenvolvimento da habilidade de produzir textos em crianças.

Em síntese, dar instruções explícitas acerca da estrutura narrativa de histórias parece ser uma boa forma de ajudá-las na produção de histórias mais elaboradas. Contrariamente ao sugerido anteriormente por Fayol (1985), e corroborando as evidências obtidas por Ferreira e Spinillo (2003), a realização de atividades de natureza metatextual auxilia a promover o desenvolvimento do esquema narrativo de histórias, tanto na produção oral quanto na escrita. As atividades de natureza metatextual produzem bons resultados sobre a produção de histórias por crianças, tanto em contextos experimentais quanto em contextos de intervenção realizados em condições similares às de sala de aula, ou seja, independentemente de as crianças serem assistidas de forma individual (Ferreira \& Spinillo, 2003) ou em grupo. Atividades de natureza metatextual são instrumentos eficazes no desenvolvimento da habilidade da criança em produzir histórias, seja oralmente (Ferreira \& Spinillo, 2003) ou por escrito.

Uma vez que a habilidade de escrever histórias, o domínio do esquema narrativo e a consciência acerca das partes de uma história são habilidades que se relacionam e se desenvolvem com o decorrer da idade e da escolaridade (Spinillo \& Simões, 2003), tudo indica que a maioria das crianças que freqüenta regularmente a escola atingirá possivelmente um bom domínio deste conhecimento. No entanto, as atividades de natureza metatextual, como as realizadas nos contextos de intervenção descritos neste trabalho, podem acelerar este processo e aprimorá-lo. As atividades de natureza metatextual são atividades que poderiam ser usadas também com crianças que encontram dificuldades relacionadas à escrita de histórias.

\section{Referências}

Albuquerque, E. B. C., \& Spinillo, A. G. (1997). O conhecimento de crianças sobre diferentes tipos de texto. Psicologia: Teoria e Pesquisa, 13 (3), 329-338.
Bazerman, C. (2006). Gêneros textuais, tipificação e interação. São Paulo: Cortez.

Fayol, M. (1985). Le récit et sa construction: um approche de psychologie cognitive. Neuchâtel: Delachaux \& Niestlé.

Ferreira, A. L., \& Spinillo, A. G. (2003). Desenvolvendo a habilidade de produção de textos em crianças a partir da consciência metatextual. In M. R. Maluf (Org.), Metalinguagem e aquisição da escrita (pp.119-148). São Paulo: Casa do Psicólogo.

Garcez, L. H. C. (2002). Técnica de redação: O que é preciso saber para bem escrever. São Paulo: Martins Fontes.

Gombert, J. E. (1992). Metalinguistic development. London: Harvester- Wheatsheaf.

Lins e Silva, M. E., \& Spinillo, A. G. (2000). A influência de diferentes situações de produção na escrita de histórias. Psicologia: Reflexão e Crítica, 13 (3), 337-350.

Marcuschi, L. A. (2002). Gêneros textuais: definição e funcionalidade. In A. P. Dionísio, A. R. Machado \& M. A. Bezerra (Orgs.), Gêneros textuais \& ensino (pp.19-36). Rio de Janeiro: Lucerna.

Rego, L. L. B. (1986). A escrita de estórias por crianças: as implicações pedagógicas do uso de um registro lingüístico. Revista de Documentação de Estudos em Lingüística Teórica e Aplicada (DELTA), 2 (2), 165-180.

Rego, L. L. B. (1996). Os critérios infantis para definir histórias. Um estudo exploratório dos critérios utilizados pelas crianças para definir histórias. In M. G. B. B. Dias \& A. G. Spinillo (Orgs.), Tópicos em psicologia cognitiva (pp.120-138). Recife: Editora Universitária da UFPE.

Shapiro, L. R., \& Hudson, J. A. (1991) Tell me a make-believe story: coherence and cohesion in young children's pictureelicited narratives. Developmental Psychology, 27 (6), 960-974.

Spinillo, A. G., \& Pinto, G. (1994). Children's narratives under different conditions: a comparative study. British Journal of Developmental Psychology, 12 (2), 177-193.

Spinillo, A. G., \& Martins, R. A. (1997). Uma análise da produção de histórias coerentes por crianças. Psicologia: Reflexão e Crítica, 10 (2), 219-248.

Spinillo, A. G. (2001). A produção de histórias por crianças: a textualidade em foco. In J. Correa, A. G. Spinillo \& S. Leitão (Orgs.), Desenvolvimento da linguagem: escrita e textualidade (pp.73-116). Rio de Janeiro: Faperj/Nau.

Spinillo, A. G., \& Simões, P. (2003). O desenvolvimento da consciência metatextual em crianças: questões conceituais, metodológicas e resultados de pesquisas. Psicologia: Reflexão e Crítica, 16 (3), 537-546.

Stein, N. L. (1982). What's in a story: interpreting the interpretations of story grammar. Discourse Processes, 5 (3-4), 319-335.

Recebido em: 4/12/2006

Versão final reapresentada em: 15/2/2008

Aprovado em: 11/3/2008 